\title{
Future Cardiovascular Risk may Vary by Fetal Presentation at Delivery
}

\author{
Takehiro Michikawa
}

Department of Environmental and Occupational Health, School of Medicine, Toho University, Tokyo, Japan

\section{See article vol. 27: 204-214}

Based on the concept of the Developmental Origins of Health and Disease $(\mathrm{DOHaD})^{1)}$, the evidence linking early-life exposures with later-life diseases is accumulated year by year. In Japan, however, limited evidence is available regarding whether early-life exposures influence non-communicable disease in adult life. Among 4,626 participants who were born between 1965 and 1974 in Ishikawa, both birth weight and percent increase in height from the age of 3 to 20 years were found to be independently associated with blood pressure and total cholesterol level at the age of 20 years $^{2)}$. Among 26,949 female nurses aged $\geq 30$ years who participated in a baseline survey of the Japanese Nurses' Health Study between 2001 and 2007, birth weight was found to be inversely associated with adult-onset diabetes status ${ }^{3)}$. Furthermore, low birth weight was found to be associated with subsequent cardiovascular risk factors, such as blood pressure and cholesterol level, in urban Japanese men and women aged between 40 and 69 as of 2007-2008 ${ }^{4}$. To explain the association between birth weight and cardiovascular risks in later life, an association of low birth weight with reduced adiponectin levels and elevated white blood cell counts has been reported in Japanese adults, ${ }^{5,}$.

In this issue of the Journal of Atherosclerosis and Thrombosis, Katsuragi et al. used the data of 1,241 city dwellers who were born between 1939 and 1968 and showed that perinatal conditions around birth, such as fetal presentation, delivery place, and lactation, are associated with cardiovascular risks in later life ${ }^{7)}$. Interestingly, they observed that participants who were born in breech presentation had a higher blood glucose level (mean level $=123.2$, standard deviation $=7.8 \mathrm{mg} / \mathrm{dL}$ ) than those who were born in cephalic presentation $(106.8,1.2 \mathrm{mg} / \mathrm{dL}$ ) (adjusted $p$-value $=0.03)$. However, lack of data from approximately $25 \%$ of participants, who were not aware of their fetal presentation at delivery, should be interpreted with caution.

Underlying mechanisms of the association between breech presentation and cardiovascular risks in later life, such as an increased blood glucose level, remain unclear. In the discussion section, the authors have mentioned the association of breech presentation with low birth weight and gestational diabetes mellitus. Breech presentation may be a marker of adverse birth outcomes. In addition, breech presentation restricts lower limb movement and likely affects bone health directly. Recently, a UK prospective birth cohort, The Avon Longitudinal Study of Parents and Children, has reported that breech presentation adversely affects bone health, such as lower limb bone mass and area, in late adolescence, particularly in women ${ }^{8)}$. This finding suggests that breech presentation is a potential risk factor for osteoporosis. Osteoporosis is known to be related to cardiovascular events ${ }^{9}$. Thus, it would be of interest to elucidate the different influences of breech and cephalic presentations at delivery on future health.

This study provides evidence linking perinatal factors with future cardiovascular diseases in Japanese population. Further evidence, which also includes environment-and lifestyle-related factors during childhood, would bring us close to the conclusion concerning the influence of prenatal conditions on cardiovascular risks in later life.

\section{Conflict of Interest}

None.

Address for correspondence: Takehiro Michikawa, Department of Environmental and Occupational Health, School of Medicine, Toho University, 5-21-16 Omorinishi, Ota-ku, Tokyo 143-8540, Japan E-mail: takehiro.michikawa@med.toho-u.ac.jp

Received: July 1, 2019 Accepted for publication: July 1, 2019

Copyright@2019 Japan Atherosclerosis Society

This article is distributed under the terms of the latest version of CC BY-NC-SA defined by the Creative Commons Attribution License. 


\section{Reference}

1) Haugen AC, Schung TT, Collman G, Heindel JJ. Evolution of DOHaD: the impact of environmental health sciences. J Dev Orig Health Dis, 2015; 6: 55-64

2) Miura K, Nakagawa H, Tabata M, Morikawa Y, Nishijo M, kagamimori S. Birth weight, childhood growth, and cardiovascular disease risk factors in Japanese aged 20 years. Am J Epidemiol, 2001; 153: 783-789

3) Katanoda K, Noda M, Goto A, Mizunum H, Lee JS, Hayashi K. Impact of birth weight on adult-onset diabetes mellitus in relation to current body mass index: The Japan Nurses' Health Study. J Epidemiol, 2017; 27: 428434

4) Katsuragi S, Okamura T, Kokubo Y, Ikeda T, Miyamoto Y. Birthweight and cardiovascular risk factors in a Japanese general population. J Obstet Gynaecol Res, 2017; 43, 1001-1007

5) Tamakoshi K, Yatsuya H, Wada K, Matsushita K, Otsuka R, Sugiura K, Kondo T, Toyoshima H. Low birth weight is associated with reduced adiponectin concentration in adult. Ann Epidemiol, 2006; 16: 669-674

6) Wada K, Tamakoshi K, Ouyang P, Otsuka R, Mitsuhashi H, Takefuji S, Matsushita K, Sugiura K, Hotta Y, Toyoshima $H$, Yatsuya H. Association between low birth weight and elevated white blood cell count in adulthood within a Japanese population. Circ J, 2008; 72: 757-763

7) Katsuragi S, Okamura T, Kokubo Y, Watanabe M, Higashiyama A, Ikeda T, Miyamoto Y. The perinatal condition around birth and cardiovascular risk factors in the Japanese general population: The Suita study. J Atheroscler Thromb, 2020; 27: 204-214

8) Tobias JH, Sayers A, Deere KC, Heazell AEP, Lawlor DA, Ireland A. Breech presentation is associated with lower adolescent tibial bone strength. Osteoporos Int, $2019 \mathrm{Apr}$ 24. doi: 10.1007/s00198-019-04945-4. [Epub ahead of print]

9) Lampropoulos CE, Papaioannou I, D’Cruz DP. Osteoporosis-a risk factor for cardiovascular disease? Nat Rev Rheumatol, 2012; 8: 587-598 